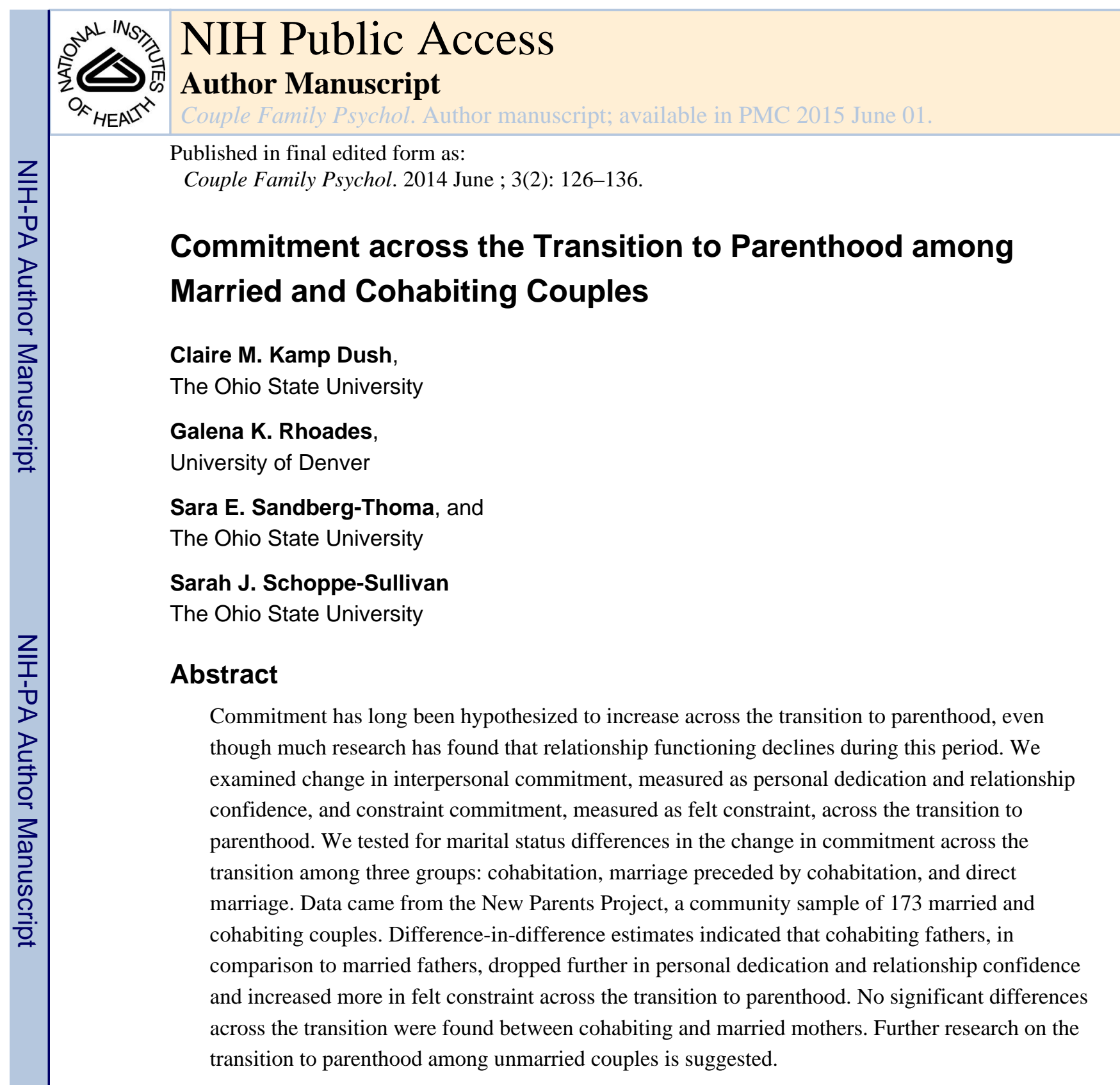

\title{
Keywords
}

transition to parenthood; commitment; dedication; confidence; constraint; cohabitation; marriage

Social scientists (Becker, 1981; Waite \& Lillard, 1991) have argued that couples become more committed to each other after having a child. Most have cited that the probability of divorce is lower for parents compared to nonparents (Waite \& Lillard, 1991), yet decades of research has found relationship quality decreases across the transition to parenthood (Belsky, Spanier, \& Rovine, 1983; Lawrence, Rothman, Cobb, Rothman, \& Bradbury, 2008). One study examined change in commitment across the transition to parenthood. Doss, Rhoades, Stanley, and Markman (2009) found that spouses became less committed across the transition; husbands and wives became less dedicated to their spouse, and husbands also became less confident in the relationship's future. Although no research has 
examined it, parents may also feel more constrained, or trapped, in their relationship and this form of commitment may be most likely to increase after the birth of a child.

Cohabiting couples in the United States, where a majority of individuals say they wish to marry and hold high expectations for the institution (Wood, Avellar, \& Goesling, 2008), may be particularly at risk across the transition to parenthood, and they have been ignored in the transition to parenthood literature. A historic $41 \%$ of U.S. children were born to unmarried parents (Hamilton, Martin, \& Ventura, 2011). Nearly $60 \%$ of these births were to cohabiting couples (Lichter, 2012), and 64\% of these couples will see their union dissolve within 5 years (Kamp Dush, 2011). No research has examined the change in commitment across the transition to parenthood among cohabiting couples in the US, whose relationship (and child) may be vulnerable if commitment drops. The purposes of this study were to test in a sample of different-sex couples 1) whether commitment, as measured by personal dedication, relationship confidence, and felt constraint, changed across the transition to parenthood, and 2) whether the change in commitment across the transition was different by marital status (cohabitation, marriage preceded by cohabitation, direct marriage). The marital literature has found that marriages preceded by cohabitation are at greater risk for poor marital functioning (Jose, Daniel O'Leary, \& Moyer, 2010), hence we distinguish marriages by premarital cohabitation.

\section{Commitment Theory}

Stanley and colleagues' model of commitment (Stanley \& Markman, 1992; Stanley, Rhoades, \& Whitton, 2010), drawing on the work of Levinger (1965, 1979), Rusbult (1980), and Johnson (1973), suggests that commitment is marked by two related constructs: dedication and constraint commitment. Dedication is a marker of an individual's desire to maintain or improve their relationship for the joint benefit of both partners. Related to dedication is the construct of confidence in the future of the relationship. Individuals who feel confident that their relationship will last behave in ways that may not always be beneficial for the self, but are beneficial for the relationship as a whole (Stanley et al., 2010). Dedication and relationship confidence represent the more personal aspect of commitment.

In contrast, constraint commitment is the extent to which one remains in their relationship because the barriers to ending the relationship are too great (Stanley \& Markman, 1992; Stanley et al., 2010). This form of commitment is more closely related to structural barriers to exiting the relationship, such as a shared mortgage. Rhoades, Stanley, and Markman (2010) showed that felt constraint (i.e., feeling trapped) predicted relationship dissolution in a sample of unmarried individuals (Rhoades et al., 2010).

\section{Commitment Across the Transition to Parenthood}

Research typically shows that parents become less satisfied with their relationship pre to postbirth (Belsky et al., 1983; Doss et al., 2009; Lawrence et al., 2008). Doss et al. (2009) found that husbands and wives also became less dedicated to their spouse, and husbands also became less confident in their relationship's future, pre to postbirth. These findings suggest that the stress of parenting or the co-occurring increases in negative interactions between partners may erode positive aspects of the relationship, including both satisfaction and the 
personal side of commitment (Doss et al., 2009). Although it has not been examined in prior research, felt constraint is likely to increase across the transition to parenthood, as the barriers to exiting the relationship increase, and the alternatives - such as decreased contact with one's child - may lead parents to feel they must continue their relationship even if they are unsatisfied. Thus, we hypothesized that aspects of commitment that are related to personal experiences of the relationship, including dedication and relationship confidence, would decrease across the transition to parenthood, while that aspect of commitment related to structural barriers, felt constraint, would increase.

\section{The Role of Marital Status}

Cohabiting individuals differ from married spouses in a variety of ways. Besides being more likely to be younger, minority, poor, and less educated (Smock, 2000), cohabitors are also less satisfied (Brown \& Booth, 1996) and much more likely to end their relationship as compared to married spouses (Manning, Smock, \& Majumdar, 2004). Even after marriage, cohabiting individuals exhibit less satisfaction and more instability, hence the marital literature has distinguished marriages preceded by cohabitation from those not (Jose et al., 2010). However differences between married and cohabiting individuals could become minimized because the cohabiting population has become more diverse with $62 \%$ of young women now cohabiting before age 25 (Copen, Daniels, \& Mosher, 2013). Indeed, recent research has been mixed with regard to the association between premarital cohabitation and marital outcomes, with some scholars finding a negative association, particularly among individuals who have cohabited with more than one individual (serial cohabitors; Lu, Qian, Cunningham, \& Li, 2012) and others finding no association (Manning \& Cohen, 2012).

However, most relationship scholars posit that nonmarital cohabitation is a less committed relationship state than marriage (Nock, 1995). Marriage is a legal union in the US and there are legal rights, obligations, and social norms associated with it, whereas cohabitation is informal and largely unregulated (Bowman, 2004), and is what sociologists call an "incomplete institution" that lacks social norms for how people should behave (Nock, 1995). For example, cohabiting couples lack a word to call their partners and often move in together without necessarily having "decided" to live together (Manning \& Smock, 2005).

Individuals in cohabiting relationships tend to be less dedicated than those who are married (Stanley, Whitton, \& Markman, 2004) and there is evidence that they may also feel more constrained. Nock (1995) used an index of the perceived costs and benefits of separation and cohabiting individuals rated their alternative lives (without their partners) as significantly better than married spouses. Based on this research, we expected that cohabiting parents would decline more in personal dedication and relationship confidence across the transition to parenthood than married parents because the more tenuous nature of cohabiting parents' commitment may decrease attractions to the relationship and increase the attractiveness of alternatives. In contrast, we expected cohabiting parents to increase more in felt constraint compared to married parents, as the birth of their child may represent the first substantial barrier to exiting their relationship; married parents already have considerable legal barriers to dissolving their union. 


\section{Gender Differences}

Evolutionary theory argues that parents invest in biological children because it increases the likelihood that children will survive to reproduce and continue the genetic line of the family (Emlen, 1995). It also highlights gender differences in the transition to parenthood (Trivers, 1972); childbirth comes with much greater time and effort costs for women in gestation, birth, and childcare. Men share a much smaller burden of childcare, even in the US where fathers have become more involved with their children over time (Bianchi, 2000). Because women tend to share a larger proportion of the burden of childcare, women likely seek to secure resources for the child. This should translate into an increased sense of dedication to the father, if he provided resources for her child. However, contrary to this perspective,Doss et al. (2009) found that wives became less dedicated to their husbands across the transition to parenthood. Thus it may be that constraint commitment increases for women because they need their partner's resources to help ensure their child's optimal development.

Evolutionary theory also suggests that men may be more attuned to mating efforts than childrearing efforts (Geary, 2000). That is, the societal goals of maintaining the population and increasing its fitness may require men, in comparison to women, to focus more on mating with multiple partners and less on rearing children. Thus, they, too, may show decreases in personal dedication and relationship confidence after childbirth. Similar to women, childbirth may also increase men's sense of being trapped, as societal norms suggest that a new child should serve as a significant barrier to dissolving the relationship. Part of the evolutionary utility of marriage is that it offers legal protections for women and children from abandonment by fathers. The lack of legal protections in cohabiting unions makes it easier for men to disengage after the birth of a child. In fact, cohabiting parents are five times as likely to dissolve their union within three years after birth compared to married parents (Osborne, Manning, \& Smock, 2007).

Gender differences in changes in commitment may also be affected by the resources in the environment. Married parents tend to have more resources, including education, money, and social support (Smock, 2000), than cohabiting parents and in low-resource environments, paternal investment in children may be more difficult and less likely to make a difference (Geary, 2000). Under low-resource conditions, natural selection would favor a quantity strategy of having several children with different mates. Hence, in a low-resource environment such as cohabiting parents are most often in, men should be less likely to invest in their offspring and romantic relationship. Thus cohabiting men may be particularly susceptible to a decline in personal commitment and an increase in constraint commitment across the transition to parenthood.

\section{Present Study}

We used data from the New Parents Project, a sample of married and cohabiting couples, to examine changes in commitment across the transition to parenthood. We hypothesized a decline in personal dedication and relationship confidence, and an increase in felt constraint, across the transition to parenthood (Hypothesis 1). We also hypothesized that cohabiting parents would decline more in personal dedication and relationship confidence, and increase 
more in felt constraint, as compared to married parents (Hypothesis 2). We hypothesized that women would decline less in personal dedication and relationship confidence, and increase more in felt constraint, as compared to men, particularly in cohabiting couples (Hypothesis 3).

\section{Method}

\section{Participants and Procedure}

Data came from the New Parents Project, a longitudinal study of the transition to parenthood in a community sample of different-sex couples ( $N=182$ couples) in a large Midwest metropolitan area (population $>200,000$ ). The study began in the $3^{\text {rd }}$ trimester of pregnancy for all couples. To be eligible to participate, both parents had to be 1) 18 or older, 2) in the labor force in the third trimester of pregnancy (employed or looking for employment) and expecting to return to work at least part-time after the birth of the child, 3) English speakers, 4) living with the child's other parent, and 5) expecting their first child. Couples were recruited through child birth education classes, newspaper advertisements, flyers, brochures, and participant referrals. Further eligibility required that parents completed the pre and postbirth assessments and reported personal dedication, relationship confidence, and felt constraint ( $n=173$ and 166 for mothers and fathers respectively). For both assessments, questionnaires were mailed to the participants two weeks before a home interview was to take place. If the participants had not completed the questionnaires by the home interview, a stamped, project-addressed envelope was left with participants to return the questionnaires. Participants were paid $\$ 40$ cash at the prebirth assessment, and at the postbirth assessment, they received a complimentary one-year membership to a local science center, $\$ 25$ cash, and a small baby gift.

Descriptive statistics of the sample are presented in Table 1 by union type: 1) married, no premarital cohabitation, 2) married, premarital cohabitation, and 3) currently cohabiting. Overall, couples had lived together between about 2 years (cohabitors) and 5 years (married, premarital cohabitation). Income ranged from 45,000 per year (cohabitors) to 93,000 per year (married, premarital cohabitation). Between $2 \%$ (married, no premarital cohabitation) and $44 \%$ (cohabitors) were impoverished. A majority of the sample was White and between 25 (cohabiting mothers) and 32 (married, no premarital cohabitation, fathers) years old. A large majority of married mothers and fathers had a college degree or more education, while a majority of cohabiting mothers and fathers had less than a college degree.

\section{Measures}

Personal dedication was measured by a subscale of the Commitment Inventory (Stanley \& Markman, 1992). This measure has been shown to be reliable in several studies and valid with both married and unmarried samples (Owen, Rhoades, Stanley, \& Markman, 2011). Participants rated four items (e.g., "I want this relationship to stay strong no matter what rough times we may encounter") on how much they agreed from 1 (strongly disagree) to 7 (strongly agree). For the pre and postbirth assessments respectively, $\alpha=.33, .65$ and $.53, .73$ for mothers and fathers respectively. Because Cronbach's alpha has been widely acknowledged as unreliable for scales with a small number of items (Sijtsma, 2009), we also 
tested structural equation measurement models for personal dedication at the prebirth assessment. For both mothers and fathers, each item loaded significantly ( $b$ ranged from 6.36 to $6.95, p \leq .05$ for each $b$ ) on a single latent variable of personal dedication, and the fit statistics were adequate to proceed to hypothesis testing (for mothers: $\chi^{2}(2)=0.36, p=.84$, RMSEA $=.00, \mathrm{CFI}=1.00$; for fathers: $\chi^{2}(2)=1.69, p=.43$, $\mathrm{RMSEA}=.00, \mathrm{CFI}=1.00$ ).

Four items from Stanley, Hoyer, and Trathen (1994) Relationship Confidence Scale measured partners' confidence in their current relationship (e.g., "I am very confident when I think of our future together"). The measure's reliability and validity has been demonstrated (e.g., Whitton et al., 2007). Each item was rated from 1 (strongly disagree) to 7 (strongly agree). For the prebirth assessment, $a=.92$ and .81 for expectant mothers and fathers respectively; at the postbirth assessment, $a=.93$ for both mothers and fathers.

One's sense of being stuck or trapped in the relationship was measured by the Felt Constraint Scale that has been shown to be reliable (Rhoades et al., 2010). Respondents rated four items (e.g., "I stay with my partner because I have to stay, not because I want to stay") from 1 (strongly disagree) to 7 (strongly agree). For the pre and postbirth assessments respectively, $a=.69, .92$ and $.82, .88$ for mothers and fathers respectively.

\section{Results}

To test the central hypotheses, we used a difference model (Allison, 1990) also known as a change score model (D. R. Johnson, 2005) or a fixed effects regression model, commonly used in econometrics. Because only the change in the outcome (i.e. change score), is examined in difference models, all time-invariant potential sources of bias are differenced out of the models. That is, difference models are robust to time-invariant differences between participants because participant scores at the postbirth assessment are compared to their own scores at the prebirth assessment . Given the large prebirth differences in social class, union duration, and commitment (see Table 1) between cohabiting parents and married parents, we believed it necessary to conduct difference models that would account for both observed and unobserved time-invariant sources of selection. Observed indicators of selection suggested that cohabiting couples were in unions of significantly shorter durations, made significantly less income, and were significantly more likely to be poor, younger, and have less education compared to married couples. Further, cohabiting mothers reported less personal dedication and relationship confidence compared to married parents, and cohabiting fathers reported less dedication and felt constraint compared to married fathers who did not live together prior to marriage.

Difference models do not account for time-variant sources of third variable bias. However, given the short time-frame between the prebirth and postbirth assessments (4 and 6 months), these threats to validity are minimized in this study. Our first step in the analyses was to conduct fixed-effects regression models with time by marital status interactions, followed by $F$ tests to test for significant differences in the change in commitment by marital status (see Table 2). Effect sizes $(d)$ were computed for both the change in commitment over time $\left(M_{\text {Postbirth }}-M_{\text {Prebirth }} / S D_{\text {Prebirth }}\right)$, as well as the difference-in-difference estimates ( $d_{\text {Marital status group 1 }}-d_{\text {Marital status group 2 }}$ ) following guidelines suggested by B. J. Becker 
(1988) and Morris and DeShon (2002) for independent-groups pretest-posttest designs. We follow Cohen (1992) guidelines for interpreting $d$ that states that $d \geq 0.20$ is small, $d \geq 0.50$ is medium, and $d \leq 0.80$ is large. Note that mothers and fathers were examined separately; hence there was no data dependency due to mothers and fathers in the same couple in the same model.

For mothers, few significant changes or marital status differences were observed. Married mothers who cohabited prior to marriage declined significantly in personal dedication and relationship confidence across the transition to parenthood. There were no significant changes in commitment across the transition to parenthood for married mothers who did not cohabit, nor for cohabiting mothers. Only one significant difference by marital status emerged in the difference-in-difference estimates. Married mothers who cohabited prior to marriage declined significantly further in personal dedication than did married mothers who did not cohabit; $d$ indicated a medium effect.

Married fathers did not change significantly in commitment across the transition to parenthood regardless of whether or not they cohabited prior to marriage. In contrast, cohabiting fathers declined significantly in personal dedication and relationship confidence, and significantly increased in felt constraint; $d$ indicated a medium decline in personal dedication, a large decline in relationship confidence, and a large increase in felt constraint. Further, difference-in-difference estimates found that cohabiting fathers declined significantly further in personal dedication, relationship confidence, and increased significantly further in felt constraint compared to married fathers regardless of whether or not they lived together prior to marriage with one exception. However, the difference-indifference estimate of the difference in felt constraint between cohabiting fathers and married fathers who did not cohabit prior to marriage only reached marginal significance ( $p$ $=.11$ ); we cautiously interpret this result given our small sample size. $d$ for the differencein-difference estimates were medium on average, though the declines in relationship confidence for the cohabiting fathers indicated large differences in comparison to married fathers. Similarly, the increase in felt constraint was also large for cohabiting fathers as compared to married fathers who lived together prior to marriage.

\section{Discussion}

As predicted, cohabiting fathers' commitment was particularly vulnerable across the transition to parenthood. Both their personal dedication and relationship confidence decreased from pre to post birth and their sense of feeling trapped in the relationship increased. The commitment of married fathers, cohabiting mothers, and married mothers who did not cohabit prior to marriage were largely immune to the stress of the transition to parenthood. However, married mothers who cohabited prior to marriage decreased in personal dedication and relationship confidence, though only significantly differently in terms peronal dedication as compared to married mothers who did not cohabit prior to marriage. Our results suggest that perhaps in part due to the combination of an environment lacking economic and human capital-related (i.e. education) resources and legal barriers in the form of marriage, cohabiting fathers are at risk for a significant decline in personal commitment to their partner, which could lead to cohabiting fathers dissolving their 
relationship with their child's mother and perhaps pursuing other mating efforts (Geary, 2000). In a representative sample of urban, cohabiting parents, the Fragile Families and Child Wellbeing Study, 34\% of fathers had children with a previous partner at the time of their child's birth, and two-thirds saw their cohabiting relationship with that child's mother dissolve within five years (Kamp Dush, 2011). Hence, our findings suggest that the decrease in personal commitment and increase in constraint commitment among cohabiting fathers may be one mechanism through which cohabiting parents' relationships are highly unstable.

For cohabiting fathers, the first or most significant barrier to exiting their relationship may have been the birth of their new child. Thus, the transition to parenthood may have been a particularly stressful event and one that made them doubt or re-evaluate their commitment to their relationship. In contrast, pregnancy itself may have served as an initial constraint for cohabiting mothers as the costs of childbirth increase at pregnancy and throughout gestation for women (Trivers, 1972). Our prebirth measure of commitment was collected only in the third trimester; future research should compare commitment across the transition to pregnancy.

Earlier relationship investments, such as the decision to marry, may have lessened the impact of the transition to parenthood on married parents' commitment to each other or sense of feeling trapped. Yet, married mothers who cohabited prior to marriage appeared to be vulnerable to declines in personal commitment across the transition to parenthood as evidenced by their significant declines in personal dedication and relationship confidence. Doss et al. (2009) found that married fathers who cohabited prior to marriage had larger sudden decreases in relationship dedication compared to married fathers who did not cohabit prior to marriage, but this finding did not hold for mothers, and there were no significant differences among married parents by premarital cohabitation status in relationship confidence. It is possible that in our sample of dual-earner couples, married mothers who had cohabited prior to marriage may have had higher expectations for an egalitarian division of labor; cohabiting couples have been found to have more egalitarian relationships in comparison with married couples (Batalova \& Cohen, 2002). Because gender role attitudes and behaviors become more entrenched after the transition to parenthood (Katz-Wise, Priess, \& Hyde, 2010) and women continue to do more than men do, even in dual-earner couples (Bianchi, 2000), married mothers who cohabited prior to marriage and may have been in more egalitarian relationships may have been more vulnerable to changing gender roles and a shift towards more parenting and household duties across the transition to parenthood. Their personal commitment may have suffered as a result. Further research into other differences in family functioning across the transition to parenthood by marital status may be warranted.

Given that cohabiting parents reported less personal and more constraint commitment at the prebirth assessment compared to married parents in general, the combination of increasing constraint commitment and decreasing personal commitment among cohabiting fathers may represent a significant risk factor for these families and the stability of their unions. This combination is one potential mechanism through which cohabiting parents are at greater risk for union dissolution than married parents (Osborne et al., 2007; Rhoades et al., 2010). There are important implications for the well-being of their children as well, as family 
instability is associated with poor child outcomes (Fomby \& Cherlin, 2007; Osborne \& McLanahan, 2007), and the early instability of cohabiting parents' relationships leaves many years when the child is in the home and at risk for further exposure to family instability.

Although this study is important in that it is the first to examine the transition to parenthood among cohabiting couples and to compare experiences across married and cohabiting parents, its limitations should also be considered. The sample was small, particularly the subsample of cohabiting couples, and was not representative of all cohabiting or married parents experiencing the transition to parenthood. These results need to be replicated in a larger, more representative sample. Further, postbirth measurement of commitment came from a single assessment at 3-months postpartum. The stress of the transition to parenthood may cause only temporary changes in commitment; however,Doss et al. (2009) found that commitment did not recover to prebirth levels with time for married couples. Longer term longitudinal research could further address this issue. Finally, the prebirth measurement of personal dedication had a low alpha. Though the results were consistent across measures, results for personal dedication should be replicated.

In conclusion, although social scientists have suggested that couples ought to become more committed across the transition to parenthood, we found little evidence of an increase in commitment for either cohabiting or married couples. In contrast, we found that fathers who were cohabiting showed decreased significantly more in personal dedication and relationship confidence, and increased significantly more in a sense of feeling trapped in their relationship, as compared to married fathers. Given that the proportion of children born to unmarried parents in the US has continually increased across the past forty years (Hamilton et al., 2011), research on relationship functioning in cohabiting families should continue so that clinical intervention and prevention efforts aimed at enhancing unmarried parents' relationships to ensure long-lasting relationships and healthy child development (e.g., Wood, McConnell, Moore, Clarkwest, \& Hsueh, 2012) could be better informed.

The preliminary findings presented in this study suggest that intervening around the time of birth may be especially important for cohabiting couples. Given that low personal dedication is a clear predictor of relationship dissolution (Rhoades et al., 2010) and that parental relationship stability is strongly associated with better child outcomes (e.g., Goodnight et al., 2012), such interventions could have a significant impact on a range of issues. Interventions that help couples, and perhaps particularly fathers, develop and deepen their commitment to each other and the future and provide communication skills to manage conflict seem warranted. There is evidence from the Building Strong Families project's Oklahoma City cite that such interventions can improve long-term stability among unmarried families (Wood et al).

\section{Acknowledgments}

Kamp Dush and Rhoades are grateful for support from the Eunice Kennedy Shriver National Institute of Child Health and Human Development (NICHD) (1K01HD056238, Kamp Dush; R01 HD047564, Stanley).The New Parents Project was funded by the National Science Foundation (CAREER 0746548, Schoppe-Sullivan), with support from The Ohio State University's Initiative in Population Research (NICHD; R24 HD058484, 1 R21 HD047943-01) and the Department of Human Development and Family Science. The contents of this paper are the

Couple Family Psychol. Author manuscript; available in PMC 2015 June 01. 
responsibility of the authors and do not necessarily represent official views of NICHD, NSF, or The Ohio State University. We thank the students who made the New Parents Project possible.

\section{References}

Allison PD. Change scores as dependent variables in regression analysis. Sociological methodology. 1990; 20(1):93-114.

Batalova JA, Cohen PN. Premarital Cohabitation and Housework: Couples in Cross-National Perspective. Journal of Marriage and Family. 2002; 64(3):743-755.

Becker BJ. Synthesizing standardized mean-change measures. British Journal of Mathematical and Statistical Psychology. 1988; 41(2):257-278.

Becker, GS. A treatise on the family. Cambridge, MA: Harvard University Press; 1981.

Belsky J, Spanier GB, Rovine M. Stability and Change in Marriage across the Transition to Parenthood. Journal of Marriage and Family. 1983; 45(3):567-577.

Bianchi S. Maternal employment and time with children: Dramatic change or surprising continuity? Demography. 2000; 37(4):401-414. [PubMed: 11086567]

Bowman CG. Legal treatment of cohabitation in the United States. Law \& Policy. 2004; 26(1):119151.

Brown SL, Booth A. Cohabitation versus marriage: A comparison of relationship quality. Journal of Marriage and Family. 1996; 58(3):668-678.

Cohen J. A power primer. Psychological Bulletin. 1992; 112(1):155-159. [PubMed: 19565683]

Copen, CE.; Daniels, K.; Mosher, WD. First premarital cohabitation in the United States: 2006-2010 National Survey of Family Growth (National Health Statistics Reports No. 64). Hyattsville, MD: National Center for Health Statistics; 2013.

Doss BD, Rhoades GK, Stanley SM, Markman HJ. The effect of the transition to parenthood on relationship quality: An 8-year prospective study. Journal of Personality and Social Psychology. 2009; 96(3):601-619. [PubMed: 19254107]

Emlen ST. An evolutionary theory of the family. Proceedings of the National Academy of Sciences. 1995; 92(18):8092-8099.

Fomby P, Cherlin AJ. Family instability and child well-being. American Sociological Review. 2007; 72(2):181-204. [PubMed: 21918579]

Geary DC. Evolution and proximate expression of human paternal investment. Psychological Bulletin. 2000; 126(1):55-77. [PubMed: 10668350]

Goodnight JA, D'Onofrio BM, Cherlin AJ, Emery RE, Hulle CA, Lahey BB. Effects of multiple maternal relationship transitions on offspring antisocial behavior in childhood and adolescence: A cousin-comparison analysis. Journal of Abnormal Child Psychology. 2012; 41:185-198. [PubMed: 22829173]

Hamilton, BE.; Martin, JA.; Ventura, SJ. Births: Preliminary Data for 2010. Hyattsville, MD: National vital statistics reports web release; 2011.

Johnson DR. Two-wave panel analysis: Comparing statistical methods for studying the effects of transitions. Journal of Marriage and Family. 2005; 67(4):1061-1075.

Johnson MP. Commitment: A conceptual structure and empirical application. The Sociological Quarterly. 1973; 14(3):395-406.

Jose A, Daniel O'Leary K, Moyer A. Does Premarital Cohabitation Predict Subsequent Marital Stability and Marital Quality? A Meta-Analysis. Journal of Marriage and Family. 2010; 72(1): 105-116.

Kamp Dush CM. Relationship-specific investments, family chaos, and cohabitation dissolution following a nonmarital birth. Family Relations. 2011; 60(5):586-601. [PubMed: 22081737]

Katz-Wise SL, Priess HA, Hyde JS. Gender-role attitudes and behavior across the transition to parenthood. Developmental Psychology. 2010; 46(1):18-28. [PubMed: 20053003]

Lawrence E, Rothman AD, Cobb RJ, Rothman MT, Bradbury TN. Marital satisfaction across the transition to parenthood. Journal of Family Psychology. 2008; 22(1):41-50. [PubMed: 18266531] 
Levinger G. Marital cohesiveness and dissolution: An integrative review. Journal of Marriage and the Family. 1965:19-28.

Levinger, G. A social exchange view on the dissolution of pair relationships. In: Huston, RLBTL., editor. Social exchange in developing relationships. New York: Academic Press; 1979. p. 169-193.

Lichter, DT. Childbearing among cohabiting women: Race, pregnancy, and union transitions. In: Booth, A.; Brown, SL.; Landale, NS.; Manning, WD.; McHale, SM., editors. Early Adulthood in a Family Context. New York, NY: Springer; 2012. p. 209-219.

Lu B, Qian Z, Cunningham A, Li CL. Estimating the effect of premarital cohabitation on timing of marital disruption using propensity score matching in event history analysis. Sociological Methods \& Research. 2012; 41:440-466.

Manning WD, Cohen JA. Premarital cohabitation and marital dissolution: An examination of recent marriages. Journal of Marriage and Family. 2012; 74:377-387. [PubMed: 23129875]

Manning WD, Smock PJ. Measuring and modeling cohabitation: New perspectives from qualitative data. Journal of Marriage and Family. 2005; 67(4):989-1002.

Manning WD, Smock PJ, Majumdar D. The relative stability of cohabiting and marital unions for children. Population Research and Policy Review. 2004; 23(2):135-159.

Morris SB, DeShon RP. Combining effect size estimates in meta-analysis with repeated measures and independent-groups designs. Psychological Methods. 2002; 7(1):105-125. [PubMed: 11928886]

Nock SL. A comparison of marriages and cohabiting relationships. Journal of Family Issues. 1995; 16(1):53-76.

Osborne C, Manning WD, Smock PJ. Married and Cohabiting Parents' Relationship Stability: A Focus on Race and Ethnicity. Journal of Marriage and Family. 2007; 69(5):1345-1366.

Osborne C, McLanahan S. Partnership instability and child well-being. Journal of Marriage and Family. 2007; 69(4):1065-1083.

Owen J, Rhoades GK, Stanley SM, Markman HJ. The Revised Commitment Inventory: Psychometrics and Use With Unmarried Couples. Journal of Family Issues. 2011; 32(6):820-841. [PubMed: 22582000]

Rhoades GK, Stanley SM, Markman HJ. Should I stay or should I go? Predicting dating relationship stability from four aspects of commitment. Journal of Family Psychology. 2010; 24(5):543-550. [PubMed: 20954764]

Rusbult CE. Commitment and satisfaction in romantic associations: A test of the investment model. Journal of Experimental Social Psychology. 1980; 16(2):172-186.

Sijtsma K. On the Use, the Misuse, and the Very Limited Usefulness of Cronbach's Alpha. Psychometrika. 2009; 74(1):107-120. [PubMed: 20037639]

Smock PJ. Cohabitation in the United States: An Appraisal of Research Themes, Findings, and Implications. Annual Review of Sociology. 2000; 26:1-20.

Stanley, SM.; Hoyer, L.; Trathen, DW. The Confidence Scale. Denver, CO.: University of Denve; 1994.

Stanley SM, Markman HJ. Assessing commitment in personal relationships. Journal of Marriage and the Family. 1992:595-608.

Stanley SM, Rhoades GK, Whitton SW. Commitment: Functions, formation, and the securing of romantic attachment. Journal of family theory \& review. 2010; 2(4):243-257. [PubMed: 21339829]

Stanley SM, Whitton SW, Markman HJ. Maybe I Do: Interpersonal Commitment and Premarital or Nonmarital Cohabitation. Journal of Family Issues. 2004; 25(4):496-519.

Trivers, RL. Parental investment and sexual selection. In: Campbell, B., editor. Sexual Selection and the Descent of Man 1871-1971. Chicago, IL: Aldine; 1972. p. 136-179.

Waite LJ, Lillard LA. Children and marital disruption. American Journal of Sociology. 1991; 96(4): 930-953.

Whitton SW, Olmos-Gallo PA, Stanley SM, Prado LM, Kline GH, St. Peters M, Markman HJ. Depressive symptoms in early marriage: Predictions from relationship confidence and negative marital interaction. Journal of Family Psychology. 2007; 21(2):297-306. [PubMed: 17605552] 
Wood, RG.; Avellar, S.; Goesling, B. Pathways to adulthood and marriage: Teenagers' attitudes, expectations, and relationship patterns. Research, MP., editor. Princeton, NJ.: 2008.

Wood RG, McConnell S, Moore Q, Clarkwest A, Hsueh J. The Effects of Building Strong Families: A Healthy Marriage and Relationship Skills Education Program for Unmarried Parents. Journal of Policy Analysis and Management. 2012 n/a-n/a. 


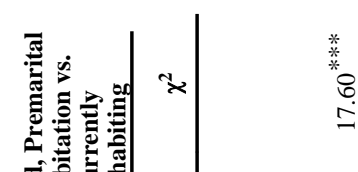

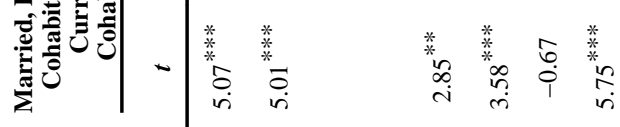

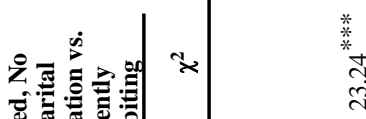

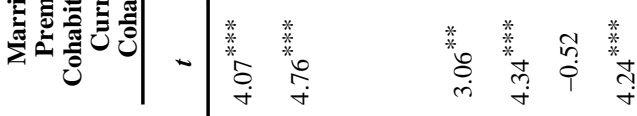

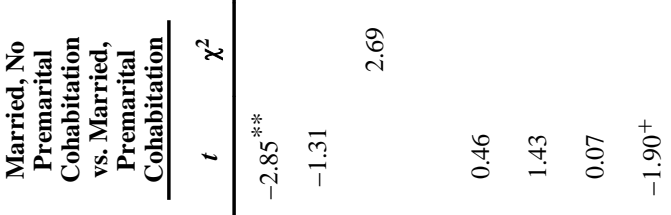

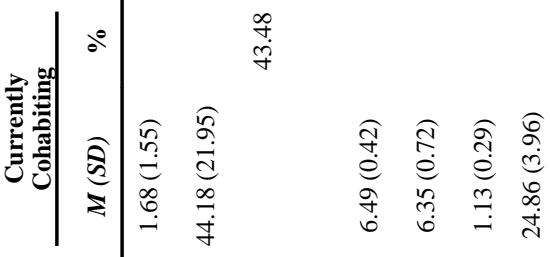

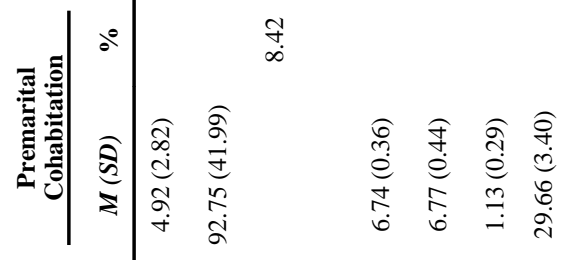

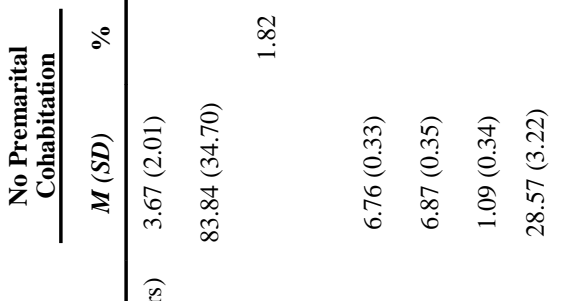

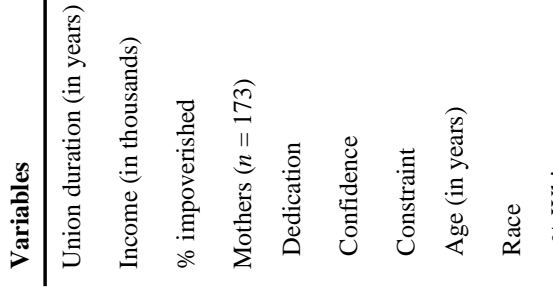

तु $\stackrel{*}{*} \stackrel{*}{m}$

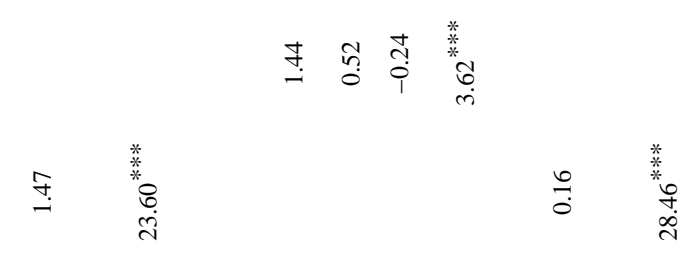

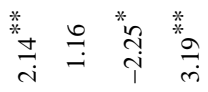

$\underset{*}{=} \stackrel{*}{\stackrel{*}{*}}$

$\stackrel{2}{-} \quad 2$

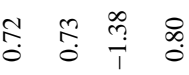

$\begin{array}{ll}\overline{2} & \infty \\ \infty & 8\end{array}$

$\begin{array}{ll}8 & 8 \\ \infty & 8\end{array}$

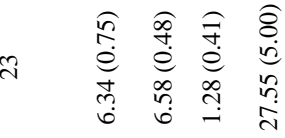

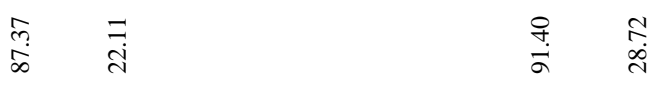

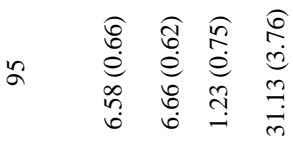

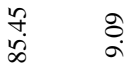

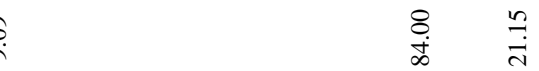

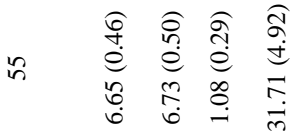




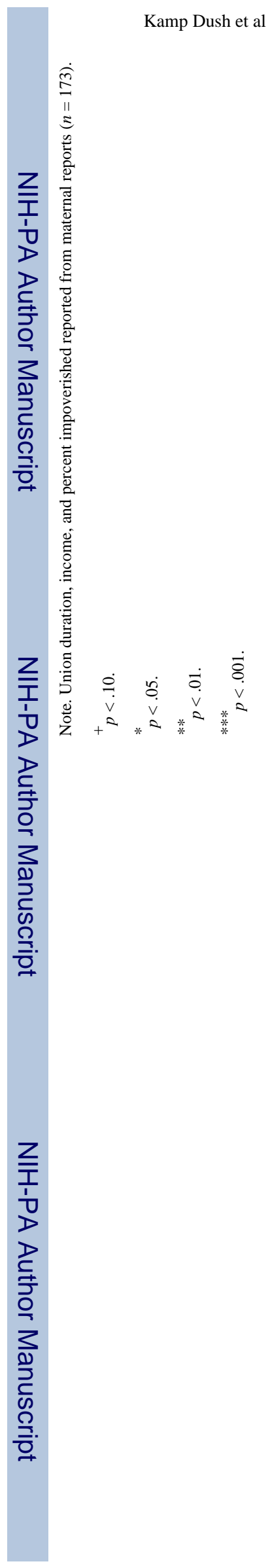

Couple Family Psychol. Author manuscript; available in PMC 2015 June 01. 


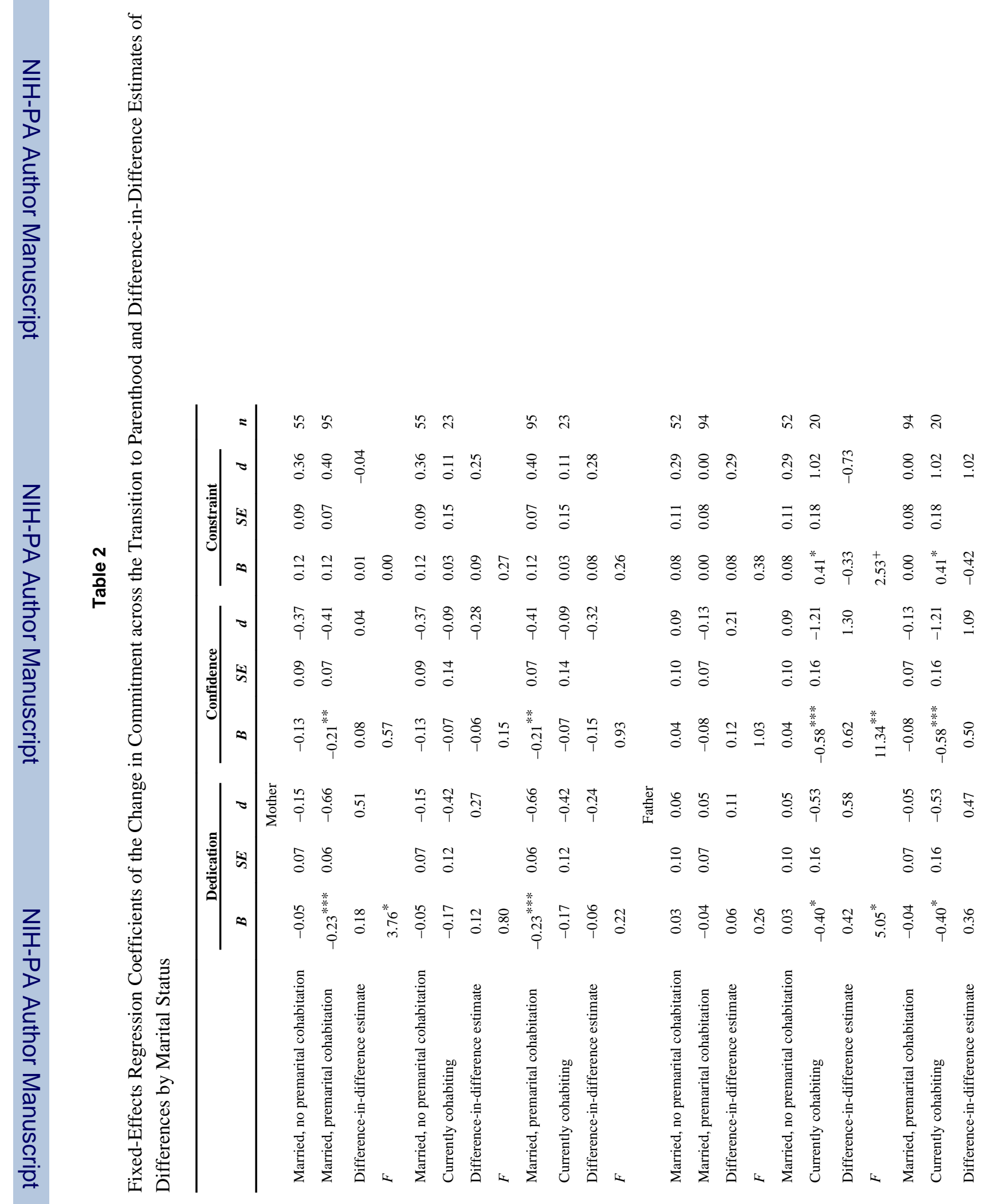




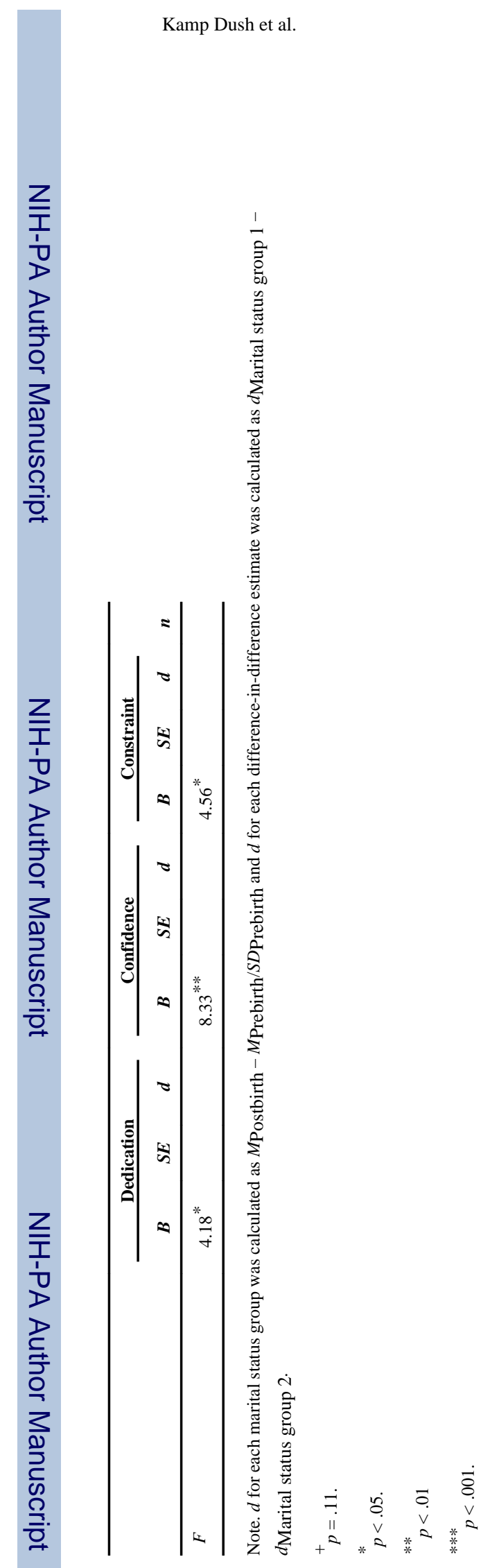

Couple Family Psychol. Author manuscript; available in PMC 2015 June 01. 